beçome steamed over for they are placed well in front of the operator's nose and the plane of his mask.

Hinges are present, (1) where the lens-bearing frame joins the struts carried forward from the face-frame, (2) where the struts join the face-frame, (3) at the junction of the side-pieces with the face-frame.

\title{
A RACK FOR OPHTHALMIC NEEDLES AND SUTURES*
}

BY

\section{H. B. Stallard}

London

ThE Figure shows a rack for holding ophthalmic needles and sutures. Its purpose is to keep these in appropriate order so that they may be picked up quickly in a needle-holder. This device consists of a plate subdivided by parallel grooves, the intervening spaces marked for No. 1, 0, 00, and 000 sutures. Attached to the plate by screws are three wire coils. The intermediate coil is set $2.5 \mathrm{~cm}$. from one of the end coils, in which is placed the needle. The long arm and the short arm of the suture are engaged in

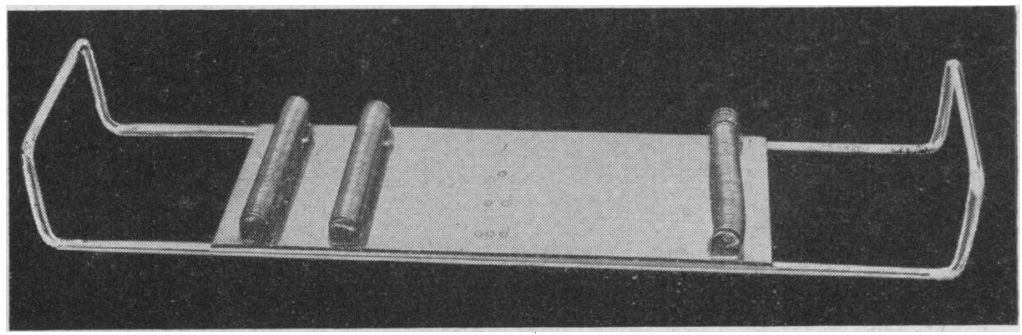

FIGURE

the intermediate coil and the long arm is carried on to the third coil. The needle and the suture lie in line within the appropriate subdivision.

The looped frame projecting beyond the end of the plate is to facilitate lifting the rack out of the sterilizer with double hooks.

The advantages of this rack are these:

(1) the needles and sutures are easily identified,

(2) they are readily picked up with a needle-holder either by the surgeon or by the nurse in charge of instruments,

(3) the suture is free from flecks of lint which often cling to silk which is sterilized in a lint roll.

\footnotetext{
* Received for publication March 10, 1950.
} 